\section{References}

1 Anderson HR. Increase in hospitalisation for childhood asthma. Arch Dis Child 1978;53:295-300.

2 MacDonald JB, Seaton A, Williams DA. Asthma deaths in Cardiff 196374: 90 deaths outside hospital. $B r$ Med F 1976;i:1493-5.

3 Crompton GK, Grant IWB, Bloomfield P. Edinburgh emergency asthma admission service: report on 10 years experience. $B r$ Med $\mathcal{f} 1979$;ii 1199-1201.

4 Anonymous. Br Med f 1979;i:1520-1.

5 Anonymous. Lancet 1979 ;ii:337-8.

- Davis B, Gett PM, Sherwood Jones E. A service for the adult asthmatic. Thorax 1980;35:111-3.

7 Department of Health and Social Security, Office of Population Censuses and Surveys, Welsh Office. Hospital Inpatient Enquiry. London: HMSO, annual.
8 Office of Population Censuses and Surveys. Mortality Statistics: Area Series DH5. London: HMSO, annual.

${ }^{9}$ Anderson HR. Trends and variations in hospital utilisation for asthma. MSc Report. University of London. 1976.

10 Anderson HR. The epidemiological value of hospital diagnostic data. In: Bennett AE, ed. Recent advances in community medicine. Edinburgh : Churchill Livingston, 1978:175-94.

$11 \mathrm{McNicol}$ KN, Williams HB. Spectrum of asthma in Children-I, clinica and physiological components. $B r$ Med $\mathcal{F}$ 1973;iv:7-11.

12 Peckham C, Butler N. A national study of asthma in childhood. $\mathcal{F}$ Epid Comm Health 1978;32:79-85.

${ }^{13}$ Logan RFL, Ashley JSA, Klein RE, Robson DM. Dynamics of medical care. London: London School of Hygiene and Tropical Medicine, 1972.

14 Gregg I. The role of the family doctor in management. In: Clarke TI Godfrey S, eds. Asthma. London: Chapman Hall, 1977:395-400.

(Accepted 9 September 1980)

\title{
Medical Communication
}

\section{The anatomy of free paper sessions}

\author{
V G TSAKRAKLIDES, E K TSAKRAKLIDES, L K KOTSIS, S S SOTIROPOULOS, \\ G PATEDAKIS, T GRIVAS, E PEKTASIDES, S LYKOUDIS
}

\section{Summary and conclusions}

The interaction between speakers, audience, and chairmen was studied by 13 investigators during a medical meeting at which 356 free papers were given before a total audience of 2483 in $\mathbf{4 8}$ sessions. A protocol was used to score 21 questions relating to the presentation, 15 to the chairman of the session, and nine to the audience. Many speakers made technical faults in presentation and their use of slides. Most chairmen failed to comply with simple rules of procedure and with the expectations of speakers and audience. The interest of the audience was affected by the performance of speakers and chairman.

Speakers should pay more attention to the technique of presentation, and organising committees of medical meetings should provide instructions to both speakers and chairmen.

\section{Introduction}

Presentations of short papers have evolved as an effective means of scientific communication. The technique of giving papers has

Training Centre for the Army Medical Corps, Arta, Greece V G TSAKRAKLIDES, MD, head of department S LYKOUDIS, PHD, assistant

Bacteriology Department, State General Hospital, Arta, Greece E K TSAKRAKLIDES, MD, bacteriologist

University of Athens, Greece

L K KOTSIS, MD, pathologist

S S SOTIROPOULOS, MD, radiologist

G PATEDAKIS, MD, radiologist

E PEKTASIDES, $M D$, paediatrician

Department of Orthopaedics, Naval Hospital, Athens, Greece T GRIVAS, MD, resident been extensively discussed, ${ }^{1-6}$ but success depends also on the interest and understanding of the audience and the competence of the chairman. ${ }^{4}$ These factors have not been adequately studied. We present a study of the interactions between speaker, chairman, and audience during a large medical meeting at which 360 free papers were presented to a total audience of 2483 people.

\section{Methods}

The investigation took place during the 5th Annual Convention of the Medical Societies of Greece in Athens on 3-6 May, 1979. Each of the papers was allotted 10 minutes for presentation and five minutes for discussion. They were presented during 48 sessions in seven conference rooms, and were evaluated by 13 investigators. The protocol (table I) contained 45 questions: 21 related to the speaker, 15 to the chairman of the session, and nine to the audience. All but two questions could be checked independently by an investigator, who arrived in the conference room well before the beginning of the session and was present throughout.

Speakers were scored on the basis of the following 10 observations a comprehensive introduction; use of manuscript; speed of presentation; facing the audience; involuntary movements; conclusions; not exceeding time; not more than 10 slides; slides comprehensible; and slides suitably demonstrated. Dependence on a manuscript was scored as 3 when minimal or absent and 0 when absolute or relative. Three other items (not exceeding time, no more than 10 slides, slides comprehensible) were noted as 2 when present and 0 when absent, while the remaining six items were marked 1 when present and 0 when absent. Thus, the total score of a presentation could vary from $0-15$. Scoring of the chairman was based on the 15 observations listed in the protocol (table I), which were noted as present or absent and marked 1 or 0 respectively.

The following independent variables were analysed statistically grading of presentations, grading of chairmen, number of questions asked by the audience per paper, noise during presentation, and noise during discussion. From studies of scatter diagrams we assumed that there was a linear correlation between grading of presentation or grading of chairmen on the one hand and number of questions or noise on the other. To test this hypothesis we determined the coefficient of determination $\left(\mathrm{r}^{2}\right)$ and the correlation coefficient $(\mathrm{r})$, which 
TABLE I-Questions asked about speakers, chairmen, and audience that were answered by the investigators for each presentation

\begin{tabular}{|c|c|c|}
\hline Speaker & Chairman & Audience \\
\hline $\begin{array}{l}\text { Before session } \\
\text { (1) Came before start of session ? Yes.... No.... Don't know.... }\end{array}$ & $\begin{array}{l}\text { (1) Came before beginning of session? } \\
\text { Yes... No... } \\
\text { (2) Began on time? Yes.... No .... } \\
\text { (3) General comment? Yes... No... }\end{array}$ & (1) Number:.... \\
\hline 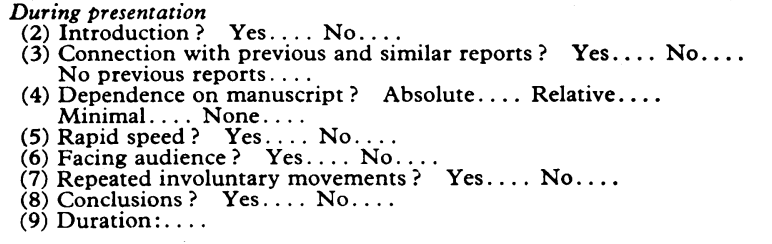 & $\begin{array}{l}\text { (4) Announcement of full title and names correct ? } \\
\text { Yes... No.... } \\
\text { (5) Attention to presentation ? Yes.... No.... } \\
\text { (6) Help to speaker? Yes... No.... } \\
\text { (7) Timing of presentation? Yes.... No... }\end{array}$ & $\begin{array}{l}\text { (2) Noise? Yes.. No.... } \\
\text { (3) Number :.... }\end{array}$ \\
\hline 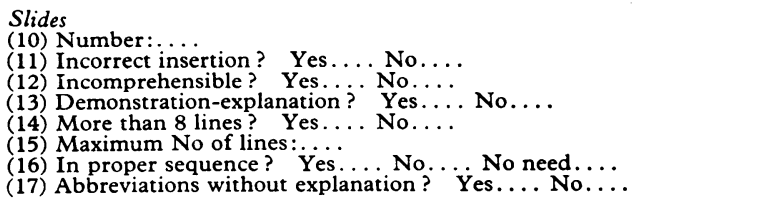 & & \\
\hline $\begin{array}{l}\text { Discussion } \\
\text { (18) Too aggressive? Yes.... No.... } \\
\text { (19) Long answers? Yes... No.... }\end{array}$ & $\begin{array}{l}\text { (8) Thanks to speaker ? Yes... No.... } \\
\text { (9) Encouragement? Yes... No.... } \\
\text { (10) Co-ordination? Yes.... No.... } \\
\text { (11) Questions ? 0, } 1,2,3 \\
\text { (12) Too long talk? Yes.... No.... }\end{array}$ & $\begin{array}{l}\text { (4) Questions: } 0,1,2,3,4,5+ \\
\text { (5) Irrelevant questions? } \\
\text { Yes... No . . . } \\
\text { (6) Prolixity ? Yes... No... } \\
\text { (7) Polite? Yes... No.... } \\
\text { (8) Noise? Yes... No... }\end{array}$ \\
\hline $\begin{array}{l}\text { After presentation } \\
\text { (20) Age: }: \text { T } \\
\text { (21) Title ? Professor, Assistant professor, Dr, Specialist, Non-specialist }\end{array}$ & 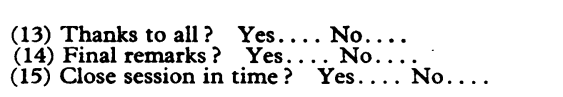 & (9) Number:.... \\
\hline
\end{tabular}

TABLE II-Scores according to academic status and age of speaker

\begin{tabular}{cccc}
\hline \multirow{3}{*}{ Scores } & \multicolumn{3}{c}{ Speakers } \\
\cline { 2 - 4 } & Total & $\begin{array}{c}\text { Professors* } \\
(\%)\end{array}$ & $\begin{array}{c}\text { Aged } \geqslant 40 \text { years } \\
(\%)\end{array}$ \\
\hline $2-8$ & 124 & 13 & 42 \\
$9-11$ & 128 & 20 & 45 \\
$12-15$ & 84 & 38 & 62
\end{tabular}

${ }^{*} \chi^{2}=18.12 ; \mathrm{p}<0.001 . \quad \dagger \chi^{2}=8.87 ; \mathrm{p}<0.05$

measure the strength of the relationship and the strength of linear association respectively. ${ }^{7}$ For the other associations the $\chi^{2}$ test for contingency tables was applied.

\section{Results}

SPEAKERS

We evaluated all but four of the 360 papers. Eighty-five (24\%) of speakers were not present when the session was due to begin. Nineteen speakers sat during their presentation and 20 did not use slides. Of the 336 speakers who used slides $60(18 \%)$ began without a comprehensive introduction. Almost half (147) depended completely on a manuscript, $74(22 \%)$ showed a relative and $49(15 \%)$ a minimal dependence, while only $60(18 \%)$ did not use a manuscript. Almost a quarter (78) talked rather rapidly, and this was often related to absolute dependence on a manuscript.

Ninety-four $(28 \%)$ speakers did not face the audience during most or all of their presentation. This was not unique to those who depended on a manuscript, and many turned their back on the audience during demonstration of slides. Others, especially junior speakers, kept their eyes fixed on the chairman or on the ceiling. Thirty-six speakers $(10 \%)$ showed repeated movements, the most common of which was pacing up and down. Presentations were incomplete and ended without conclusions in $44(13 \%)$ of papers.

No fewer than 120 speakers ( $34 \%$ ) exceeded the allocated time of 10 minutes, and 12 talked from 16 to 40 minutes. The number of slides varied from 0 to 94 , but $225(67 \%)$ speakers kept within our arbitrary limit of 10 slides. All but one of the 21 speakers who used more than 24 slides exceeded the allotted time. Sixty-six per cent (222) of presentations included incomprehensible slides, most of which were tables with many lines or many words per line, or both. In 43 presenta- tions the number of lines exceeded 20, and up to 41 lines were noted. Slides were improperly shown in $18 \%$ of presentations.

Most speakers achieved an above-average number of scores (fig 1); $124(37 \%)$ presentations were classified as low (2-8), $128(38 \%)$ as medium (9-11), and $84(25 \%)$ as high (12-15). Scores obtained by professors and by speakers over the age of 40 were significantly better than those of their more junior and younger colleagues (table II).

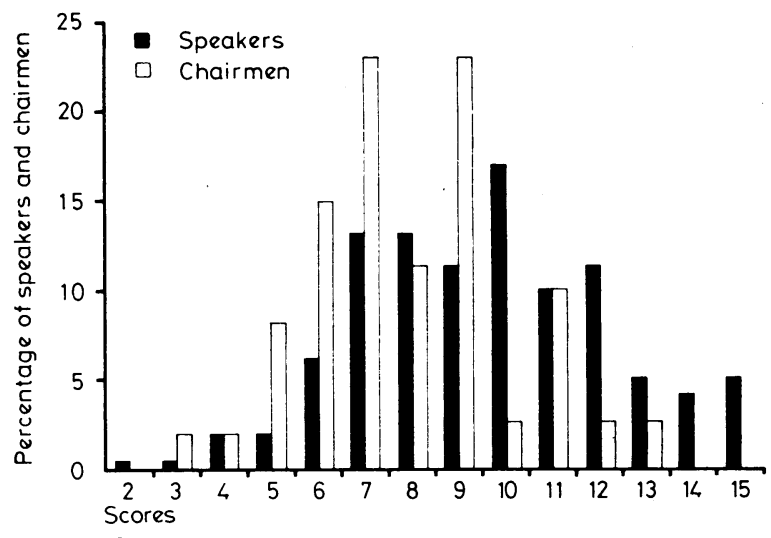

FIG 1 -Scores achieved by speakers and chairmen.

\section{CHAIRMEN}

A total of 48 chairmen presided over the 360 presentations, there being usually eight papers per session, and they all announced papers correctly. Only nine were careful in helping the speaker with microphone, pointer, and lights, and only 16 timed the presentations. The majority (40) thanked the speaker at the end.

The role of the chairmen in controlling discussion was generally poor. Only 16 encouraged discussion, 14 co-ordinated it adequately, and nine put questions to each speaker. In two sessions, each of eight papers, no questions were asked either by the audience or chairman, while in eight sessions the chairman monopolised the discussion. The behaviour of chairmen at the beginning and end of sessions was also poor. Thirty-eight of the 48 were present in the conference room before the beginning or at the scheduled time of the session, and 18 made a general comment before the announcement of the first paper, 
but only 11 began on time. At the end 29 chairmen thanked the audience and speaker, but only two summarised briefly the papers and drew the session to a conclusion. Thirty-six sessions ended on time and finished 10 to 45 minutes earlier than scheduled. But 10 were delayed longer than 30 minutes and up to 90 minutes, with consequent severe disruption of the programme.

\section{AUDIENCE}

The total number of listeners was 2483 , and the average audience per session was $40-50$. In five of the 48 sessions the number of participants was low (20-30) and in five high (80-130). At the time the session was scheduled to begin the audience ranged from $3 \%$ to $75 \%$ of the maximum number reached, which occurred around the middle of the session or later.

No discussion followed 70 presentations. Altogether 669 questions were asked, giving a mean of $2 \cdot 2$ questions per paper. The number of questions per session and the mean number of questions per free paper were not related to the size of the audience or to the order in which the papers were presented. There was a weak positive linear correlation $(0.08)$ between the score for presentations and the number of questions asked (table III). A scatter diagram suggested a curvilinear relationship indicating that there were at least two kinds of questionsthose arising from real interest, and others due to muddled presentation. A stronger coefficient $(0 \cdot 135)$ was found between the number of questions and the chairman's score (table IV), and comparison with the compliance of both chairman and speaker indicated a similar distribution and correlation coefficient $(r=0.133)$ and coefficient of determination of 0.05 (fig 2).

TABLE III-Number of questions in relation to speaker's score

\begin{tabular}{|c|c|c|c|c|c|c|c|c|c|c|c|c|c|c|}
\hline \multirow{2}{*}{$\begin{array}{l}\text { No of } \\
\text { questions }\end{array}$} & \multicolumn{14}{|c|}{ Speaker's score } \\
\hline & 2 & 3 & 4 & 5 & 6 & 7 & 8 & 9 & 10 & 11 & 12 & 13 & 14 & 15 \\
\hline $\begin{array}{l}0 \\
1 \\
2 \\
3 \\
4 \\
5 \\
6 \\
7 \\
8 \\
9\end{array}$ & 1 & & $\begin{array}{l}1 \\
4 \\
1 \\
1\end{array}$ & $\begin{array}{l}2 \\
2 \\
2\end{array}$ & $\begin{array}{l}5 \\
1 \\
4 \\
6 \\
2 \\
1\end{array}$ & $\begin{array}{l}6 \\
9 \\
8 \\
8 \\
3 \\
1 \\
2\end{array}$ & $\begin{array}{r}8 \\
11 \\
6 \\
7 \\
3 \\
2 \\
1 \\
3\end{array}$ & $\begin{array}{r}11 \\
13 \\
4 \\
2 \\
2 \\
2 \\
1 \\
1 \\
1\end{array}$ & $\begin{array}{r}13 \\
8 \\
7 \\
12 \\
4 \\
4 \\
1\end{array}$ & $\begin{array}{l}7 \\
8 \\
5 \\
5 \\
4 \\
1 \\
1 \\
1\end{array}$ & $\begin{array}{l}7 \\
8 \\
6 \\
5 \\
6 \\
2 \\
1 \\
3\end{array}$ & $\begin{array}{l}3 \\
6 \\
3 \\
2 \\
1 \\
1\end{array}$ & $\begin{array}{l}2 \\
3 \\
2 \\
2 \\
3 \\
1 \\
1\end{array}$ & $\begin{array}{l}3 \\
2 \\
2 \\
1 \\
3 \\
2 \\
1 \\
1\end{array}$ \\
\hline
\end{tabular}

TABLE IV-Number of questions in relation to chairman's score

\begin{tabular}{|c|c|c|c|c|c|c|c|c|c|c|c|}
\hline \multirow{2}{*}{ No of questions } & \multicolumn{11}{|c|}{ Chairman's score } \\
\hline & 3 & 4 & 5 & 6 & 7 & 8 & 9 & 10 & 11 & 12 & 13 \\
\hline $\begin{array}{l}0 \\
1 \\
2 \\
3 \\
4 \\
5 \\
6 \\
7 \\
8 \\
9\end{array}$ & $\begin{array}{l}4 \\
1\end{array}$ & $\begin{array}{l}2 \\
3 \\
2\end{array}$ & $\begin{array}{r}15 \\
2 \\
2 \\
1 \\
1 \\
5\end{array}$ & $\begin{array}{r}10 \\
8 \\
7 \\
11 \\
3 \\
3 \\
1 \\
1 \\
1\end{array}$ & $\begin{array}{r}11 \\
14 \\
12 \\
5 \\
11 \\
4 \\
1 \\
2 \\
2 \\
1\end{array}$ & $\begin{array}{r}11 \\
12 \\
3 \\
8 \\
1\end{array}$ & $\begin{array}{r}12 \\
20 \\
14 \\
15 \\
10 \\
5 \\
1 \\
2 \\
2\end{array}$ & $\begin{array}{l}1 \\
1 \\
1 \\
2 \\
1 \\
1\end{array}$ & $\begin{array}{r}3 \\
13 \\
6 \\
7 \\
1 \\
3 \\
1 \\
1\end{array}$ & $\begin{array}{l}1 \\
1 \\
1 \\
1\end{array}$ & $\begin{array}{l}1 \\
1 \\
3 \\
1 \\
2\end{array}$ \\
\hline
\end{tabular}

Noise during presentation was noted in 56 papers in 26 sessions. It was not related to the mean number of the audience, but appeared to be associated with the grade of the presentation, occurring in $24 \%$ of poor and $14 \%$ of good papers. Similar differences were observed between noise and the performance of chairmen, but neither were statistically significant.

\section{Discussion}

A large body of information was collected on the technique of presenting free papers, the performance of chairmen, and the response of the audience, which we hope will be useful to speakers and organisers at scientific meetings. The study was carried out without the knowledge of the participants, and their performance was not affected. One disadvantage was that 13 investigators took part, but a general rehearsal well before the convention and several meetings of all investigators minimised subjective factors and ensured a satisfactory level of agreement in subsequent scoring.

Evaluation of papers was based on 10 rather arbitrarily selected criteria cited as important in presenting scientific work. ${ }^{1-4}$ While only 15 presentations satisfied all ten of these, most scored eight or more. Despite the fact that all chairmen were elected presidents of societies and most were of high academic standing and familiar with scientific sessions, most failed to comply with the basic demands of the scientific programme and with the expectations of speakers and audience. The interest of an audience contributes greatly to the success of a convention, but is difficult to measure. We chose two rather

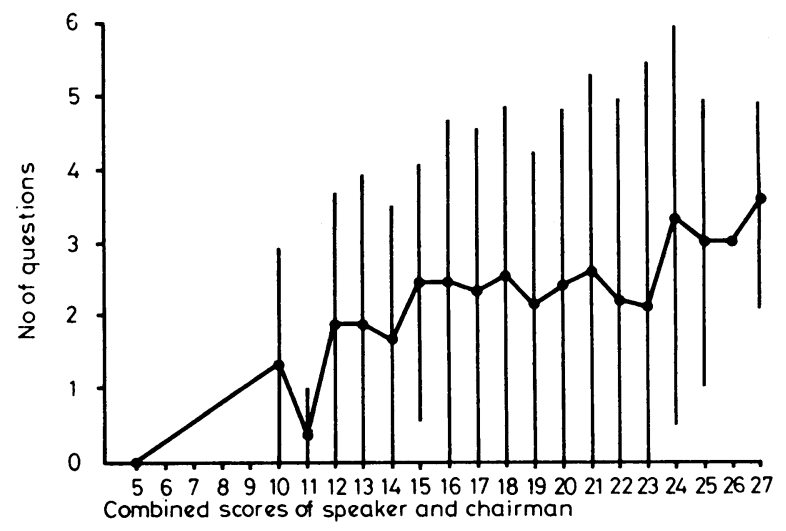

FIG 2-Mean number of questions per paper in relation to combined scores of speaker and chairman. Vertical bars indicate $90 \%$ confidence limits.

arbitrary criteria as indicators of interest-namely, the number of questions asked after the paper and the frequency of noise during its presentation. When a good speaker was combined with a competent chairman the number of questions was much higher than when either was poor. The amount of noise was also inversely related to the quality of presentation. These two findings suggest that competent speakers and chairmen hold the attention of an audience, which remains silent during the papers and asks more questions at the end. But these are clearly not the only factors. For example, a good communication, well presented, may fail to elicit any discussion, because the subject has been well delineated and no more needs to be said, while a poorly presented paper may lead to a technical debate on methodology and meaning. ${ }^{5}$

We are grateful to Doctors $\mathrm{P}$ Economopoulos, $\mathrm{P}$ Efstathiou, D Pektasides, and $M$ Stathis and to Misses $S$ Efstathiou, V Efstathiou, $M$ Kotsis, and $S$ Papaioannou for their help in carrying out this study.

\section{References}

${ }^{1}$ Hawkins CF. Speaking at meetings. Lancet 1964 ;i :261-3.

2 Ludwig JN. A letter to the next speaker. Mayo Clin Proc 1973;48:807-8.

3 Doxiades S. How a paper is presented. In: Volume dedicated to Thomas Doxiades. Athens: University of Athens, 1975:162-72. (Greek.)

4 Tsakraklides V. The art and technique of scientific meetings in hospitals. Iatr Epith En Dyn 1976;10:395-400. (Greek.)

5 Dudley $\mathrm{H}$. The presentation of original work in medicine and biology. Edinburgh: Churchill Livingstone, 1977.

${ }^{6}$ Evans M. The abuse of slides. Br Med f 1978;i:905-8.

7 Huntsberger DV, Leaverton PE. Statistical inference in the biomedical sciences. Boston: Allyn and Bacon, 1970.

(Accepted 22 September 1980) 